\section{DR. ROBERT LEE AND DR. SIMPSON.} To the Editor of The Lavoer.

Sir,-At a meeting of the Lond on Medico-Chirurgical Society, held on January 14th last, (and a report of which is given in The IaAnCET of Jan. 18th and 25th, pp. 81 \& 93,) it was stated to the Society by Dr. Robert Lee, that at the dissection of a case in which ovariotomy had been performed by Mr. Lizars, some twenty-five years before, I considered the tumour ovarian, until the two ovaries were sbown me at the dissection. The following letter to Dr. Lee will show how very far he was from stating what was true, when he made such a statement.

Edinburgh, 52, Queen-street, Feb. 3, 1851.

Dear Sir, - At the last, or one of the last meetings of the Medico-Chirurgical Society, you adduced a private letter sent to you by Mr. John Lizars, of Edinburgh, stating, in relation to one of his published cases of ovariotomy, that "Dr. Simpson, on inspecting it, pronounced it to be ovarian, but in looking to the ovaria, they were both found healthy."

Mr. Lizars was not present at the dissection; and the statement which you thus gave to the Medico-Chirurgical Society was altogether incorrect.

Dr. Myrtle had charge of the patient and of the dissection; and $I$ inclose to you a letter from that gentleman, stating, that I was the first to point out at the dissection that the two ovaries were quite unaffected. The tumour was, as you are aware, a fibrous tumour, arising from the fundus of the uterus.

Let me merely add, that $I$ have long giren up the idea that ovarian tumours (such as this was supposed to be a quarter of a century ago, when Mr. Lizars operated) ever remain stationary for any long term of years. Fibrous tumours, however, of the uterus, often enough remain latent, and without increase for a great length of time. And this simple distinction led me, a priori, to doubt whether the tumour in question could possibly be ovarian.

I write this, in order that you may, at the next meeting of the Medico-Chirurgical Society, set the Society right on a point which you thus thought fit to lay before them. I scarcely could have fancied it worthy of being mentioned to such a Society, whether I was right or not right, at the dissection and diagnosis of a case. But as you considered it worthy of the observation of the Society that I was in error in regard to the case, you will, I doubt not, now equally consider it worthy of their observation, that it was you who were inad vertently in error in making the statement.

To Dr. Lee. Yours, \&c.

Dr. Lee having refused to correct in any way the mis-state ment which he made, I hope the Fellows of the MedicoChirurgical Society will pardon me taking the present, as the readiest means, of correcting the erroneous statement publicly made to them by one of their own body.

Again, at the last meeting of the Medico-Chirurgical Society, (as reported in your journal of the $\varepsilon$ th instant,) it would appear that Dr. Lee thought fit to misrepresent to the Society another case in which I was concerned, and published an account of, (see The Lancet, for 1847, vol. ii. p. 381.) Dr. Lee stated to the Society, that in a case of mollities ossium, $I$ intended to perform the Cxsarian section, "when the sacrum was straight above, so that its promontory did not probably encroach upon the brim," hence attempting to lead the Fellows to the untrue inference that the pelvis was not contracted to such an extreme degree as to require such an operation. But he deliberately suppresses the two facts, first, that the outlet was so greatly contracted, that it was under an inch in its transverse diameter, and about two inches in its conjugate: and, secondly, that the dead and putrid child was so diffuent and decomposed, that it was passed readily after its birth, through an artificial aperture one-eighth of an inch in widtb, and two and three-eighths of an inch in length.

Perhaps most of your readers may think it unnecessary to point out these two instances of misrepresentation on Dr. Lee's part; the one consisting in a suggestioffalsi, which he refuses to recall, and the other presenting an equally marked instance of the suppressio-veri. But I trust they will excuse my alluding to them in your pages, as $I$ have no other way of refuting publicly the ridiculous and disengenuous charges which they contain. They afford, also, I fear, only too common instances of the type of misrepresentation in which Dr. Lee indiscreetly indulges himself in those painful fits of furor obstetricans against all his professional brethren, under which he, from time to time, so unhappily suffers. Is it right for the Medico-Chirurgical Society to abet these morbid attacks in Dr. Lee? Is it kind to Dr. Lee himself to encourage him in their open and public manifestation?

Edinburgh, Feb. 1851.

\section{ANALYTICAL SANITARY COMMISSION. Notrces or tHe Press.}

The Times, February 20 th.

"The last two subjects comprised in the sanitary papers of The LaNCET have been pepper and its adulterations, and water and its impurities. Out of fourteen samples of pepper purchased before the recent Government prosecutions and convictions, it appears that more than half were adulterated, linseed, mustardseed, wheat-flour, and pea-flour being the articles employed. Of twenty-nine samples subsequently purchased only seven were adulterated. It is pointed out, however, that as the convictions were fire or six only, and the number of traders who sell pepper is about 9,000 , the effects of the interference are likely to be brief, while at the same time it is hard to see the justice of pursuing such cases when the use of chicory for the adulteration of coffee is constantly palliated by the Chancellor of the Exchequer. With regard to the impurities of water, drawings are given of the microscopic appearances of the water of the Thames at Richmond and Waterloo-bridge, and also of that supplied by the Grand Junction and West Middlesex Companies, all of which are calculated to sustain the anxious degree of interest which prevails on the great question of the future supply."

The Pictorial Times (Lady's Newspaper), Feb. 8th.

"The time has come when the public has a right to investigate the dealings of tradesmen, and to be informed where they can take their money with some assurance that they will receive a genuine article in return. And though the material merits of the case deserve, as affecting health and the rights of trade, the first consideration, it is not unworthy the national character to look upon it as affecting the reputation of our tradesmen. If we are a nation of shopkeepers, let us be at all events honest in our rocation. ... We confess that, looking at the subject with a view to this consideration, it is humiliating to think that an association should be recommended, with every show of necessity for its interference, whose object it should be to test from time to time the genuine character of all articles of consumption, and issue circulars containing lists of the establishments whence deceptive articles have been vended. Painful as it would be to subject our provision shopkeepers to such a police, it is nevertheless necessary."

$$
\text { Punch, Feb. } 12 t h \text {. }
$$

"The Lancet's Detecrive Force.-Our contemporary The LANCET has conferred a great boon on the public by establishing a new order of constabulary, which may be called the scientific detective police.

"In his researches into this rascality, ThE Lancer's policeman is assisted by a microscope, which, in throwing light on the fraud in question, exerts a power far superior to that of the common bull's eye. By the help of this instrument, an immense quantity of villanous stuff has been discovered in coffee, arrowroot, and other substances sold for nutriment, and, some of them, "particularly recommended to invalids." THE LANCET seconds the exertions of its intelligent officer by spiritedly publishing the addresses of the rogues at whose swindling establishments the samples of rubbish were purchased. If any of the knaves thus pilloried in The Lancet, abetted by a disreputable attorney and a dishonest barrister, endeavour to arenge themselves through the technicalities of the law, Punch hopes they will meet with twelve true men in the jury-box who will scout both them and their legal accomplices out of court."

\section{Shipping Gazette.}

"Adurterated Coftee.-A sum of $£ 1500$ has been subscribed by merchants interested in colonial coffee, for the prosecution of grocers and others adulterating coffee with other substances than chicory."

\section{ftrexical \$2ews.}

Apporntment.-Dr. W. H. Parsey, Assistant Medical Officer of the Devon County Lunatic Asylum, is appointed Medical Superintendent of the Warwick County Asylnm.

Honorary Distinction.-The Emperor of Russia has conferred the decoration of a Commander of the Order of Stanislaus upon Dr. Lullement, a physician of Rio de Janeiro, in consideration of his valuable medical services to subjects of Russia during the prevalence of the recent yellow fever epidemic in that city. 